\title{
Living Labs as open innovation systems for knowledge exchange: solutions for sustainable innovation development
}

\section{Dimitri Schuurman*, Bastiaan Baccarne and Lieven De Marez}

iMinds Research Group for Media and ICT (MICT),

Communications Department,

Ghent University,

Korte Meer 7-9-11, 9000 Gent, Belgium

Email: dimitri.schuurman@iminds.be

Email: bastiaan.baccarne@ugent.be

Email: lieven.demarez@ugent.be

*Corresponding author

\author{
Carina Veeckman and Pieter Ballon \\ iMinds-SMIT, \\ Vrije Universiteit Brussel \\ Pleinlaan 9 - 2nd floor, 1050 Brussels, Belgium \\ Email: Carina.veeckman@iminds.be \\ Email: Pieter.Ballon@vub.ac.be
}

\begin{abstract}
In nowadays knowledge economy, no more general 'best practice' innovation management exists. Within this paper we investigate the potential of Living Labs as open innovation systems that foster different knowledge transfers amongst the actors participating in them. By means of an in-depth case study research we explore a variety of hypotheses abstracted from the open innovation literature on knowledge transfers and other variables influencing exchange and collaboration in open innovation systems. We conclude that given certain criteria are met, Living Labs can be a solution for sustainable innovation development.
\end{abstract}

Keywords: open innovation; knowledge flows; Living Labs; innovation ecosystems; user innovation; systemic innovation; user-centric innovation; SME; stakeholder roles; fibre-to-the-home; FTTH; testbed; infrastructure.

Reference to this paper should be made as follows: Schuurman, D., Baccarne, B., De Marez, L., Veeckman, C. and Ballon, P. (2016) 'Living Labs as open innovation systems for knowledge exchange: solutions for sustainable innovation development', Int. J. Business Innovation and Research, Vol. 10, Nos. 2/3, pp.322-340.

Biographical notes: Dimitri Schuurman is a Senior Researcher at the iMinds Media and ICT (MICT) research group and is responsible for the methodology of living lab projects facilitated by iMinds iLab.o. His involvement in Living Labs started in 2010 with the Mediatuin and LeYLab Living Labs. To date, he 
has managed over 30 concrete Living Lab projects that deal with new media and innovative use of ICT. He is currently finishing his $\mathrm{PhD}$ on Living Labs at Ghent University in Belgium.

Bas Baccarne started as a Researcher at iMinds-MICT in October 2012. Also being part of iMinds-iLab.o, he worked as a Living Lab User Researcher for several SME and start-up cases, with an academic focus on the possibilities and limitations of user-centric innovation development ecosystems. In October 2013, Bas became a Teaching Assistant for Prof. Dr. Lieven De Marez for the courses 'Media and ICT: innovation research', 'Media, Market and ICT' and 'Introduction to new communication technologies'. Besides these activities, $\mathrm{He}$ is also working on a $\mathrm{PhD}$ about the convergence between smart cities and Living Labs.

Lieven De Marez is Research Director of the iMinds Media and ICT (MICT) research group and teaches on the topics of innovation research and new communication technologies in the Department of Communication Sciences at Ghent University in Belgium. MICT is one of 16 research groups within iMinds and Lieven is also part of the management team of iLab.o, iMinds' facilitating infrastructure for Living Lab research.

Carina Veeckman is working in the User Research Department of iMinds-SMIT since 2011. She is active in different user-oriented projects; and her main expertise is within the domain of Living Labs. Within the Flemish Living Lab Platform (ICT Living Lab), she is doing research on several cases and coordinating the panel together with the panel management of ilab.o. She has gained experience in both quantitative and qualitative methods, such as in-depth interviews, focus groups, surveys and clustering.

Pieter Ballon is Director Living Labs at iMinds and Professor at the Vrije Universiteit Brussel in Belgium. He also the Heads of iMinds' Market Innovation and Sector Transition research team, specialising in new business models for the telecommunications and media industries. He leads various national and international projects on open innovation platforms, real-life ICT experiments, and business models for media and ICT services. Since 2009, he is the International Secretary of the European Network of Living Labs. From 2006 to 2007, he coordinated the joint research on business models for future mobile IP-based systems of the Wireless World Initiative (WWI) in the EU Sixth Framework Programme.

This paper is a revised and expanded version of a paper entitled 'Open innovation systems for value creation and knowledge exchange: results from the Flemish LeYLab Living Lab' presented at the 4th ENoLL Summer School, Manchester, UK, 27-30 August 2013.

\section{Introduction}

In the transition towards a knowledge economy, innovation is becoming more and more important for companies to remain competitive in an increasingly global economy. However, high rates of failure still illustrate the need for an adequate management of innovation, which includes selecting the right tools and methods in order to structure and optimise innovation processes (Brem and Viardot, 2013). For companies, it is necessary 
to attain an optimal level of ambidexterity, or the capability to explore external knowledge and valorise or exploit this knowledge for internal benefit (Andriopoulos and Lewis, 2009).

Traditionally, Europe scored high in terms of research (exploration), but underperformed in terms of market success (exploitation), a phenomenon referred to as the 'European paradox' (Almirall and Wareham, 2011). In order to overcome this paradox, several initiatives were kickstarted on the European policy level, such as the promotion and support of industry-university links and relationships (Perkmann and Walsh, 2007). A specific case of industry-university relationships are so-called Living Labs, which also received considerable support from the European level starting in 2006 (Dutilleul et al., 2011).

Within this paper, we will explore the value of Living Labs as a possible solution for the 'innovation paradox', as they facilitate university-industry relationships, but also relationships between large companies and SMEs, start-ups, entrepreneurs, and, last but not least, involve the end-users themselves, commonly referred to as public-private-people partnerships (4P's) (Westerlund and Leminen, 2011). Such collaboration between different types of actors in a structural way has the opportunity to unlock knowledge on several levels, to create value and to obtain different goals which would not (as easily) be possible without the existence of such networks, which can be seen as a solution for the innovation management challenges companies have to deal with (Pyka and Küppers, 2002). In order to fully understand the dynamics and benefits of such ecosystems, Perkmann and Walsh (2007) argue that more attention needs to be paid to the specificities and roles of networked inter-organisational relations within these kinds of networks to help resolve the open questions in this area of research. Therefore, we will use an open innovation perspective to analyse the roles of the various actors within the Living Lab and the knowledge and technology transfers that occur during the Living Lab operations and cases.

We will explore and analyse this open innovation and systemic view on the Living Lab-phenomenon by means of an in-depth case study analysis of LeYLab, a Living Lab based upon an experimental fibre-to-the-home (FTTH) network in a neighbourhood in the City of Kortrijk, Belgium.

\section{Open innovation and knowledge transfers}

Traditionally, innovation was viewed as an inherently closed process with most operations running inside the boundaries of the company and R\&D processes taking place in secretive in-house laboratories. Company knowledge and technologies were protected and kept safe from external influences. This view on innovation management can be characterised as 'closed innovation' or the 'vertical integration model' (Chandler, 1977). More recently, this closed, vertically integrated model has been challenged and replaced by a distributed view on innovation and innovation management (Bogers and West, 2012). The first acknowledgement of distributed innovation processes can be found in the seminal works of von Hippel (1976) who pointed out to the existence of user innovation. This eventually led to the so-called user innovation framework which investigates the circumstances under which users start innovating themselves and the characteristics these innovative users display (Sawhney and Prandelli, 2000; von Hippel, 2005). 
A second major framework building further on the notion of distributed innovation is open innovation, which took shape in the beginning of the 00s. Chesbrough (2005) defined open innovation as a nonlinear innovation process with more cooperation between internal R\&D departments and the outside world, and with companies benefiting from the synergies associated with this collaboration. Open innovation assumes that firms can and should use external ideas as well as internal ideas (Chesbrough, 2003). Factors that have favoured the shift towards a more open innovation model include increased job mobility (Cooper, 2001), the recognition of decentralised knowledge (Evans and Wolf, 2005) and shorter product life cycles (van de Vrande et al., 2009).

From the perspective of a single firm, the usual level of analysis in open innovation research, the whole concept of open innovation is grounded on the premise that opening the internal innovation process of a firm yields extra value (Chesbrough et al., 2008). This openness is attained by enabling both inbound and outbound knowledge transfers: internally acquiring external knowledge ('buying') and externally exploiting internal knowledge assets ('selling'), a phenomenon that is referred to as two sides of openness (Torkkeli et al., 2009) or the 'coupled process' of open innovation (Enkel et al., 2009). Besides (immaterial) knowledge, materialised knowledge in the form of technologies can also be the subject of inbound or outbound movements, processes that are referred to as 'technology acquisition' and 'technology exploitation' (Lichtenthaler, 2011). Knowledge and technology transfers are key processes that have been studied in open innovation literature.

Two main concepts used to classify open innovation practices are technology or knowledge exploitation versus exploration. Purposive outflows of knowledge, technology or knowledge exploitation, implies innovation activities to leverage existing technological capabilities outside the boundaries of the organisation. Purposive inflows, which we will refer to as technology or knowledge exploration, relates to innovation activities to capture and benefit from external sources of knowledge to enhance current technological developments (van de Vrande et al., 2009). In a fully open setting, firms combine both technology exploitation and technology exploration in order to create maximum value from their technological capabilities or other competencies (Chesbrough and Crowther, 2006; Lichtenthaler, 2011). Initially, in open innovation research this was studied within firms (inter-firm) or between firms (intra-firm), whereas later open innovation studies from a user innovation perspective examine how firms can collaborate with users in order to facilitate a process of external exploration as well (West and Lakhani, 2008). However, both processes have different hypothesised spillovers: within open innovation research, these knowledge and technology spillovers are situated amongst firms in an exchange or pecuniary modus, whereas in user innovation research, these spillovers from users to producers are not pecuniary in nature (Bogers and West, 2012). Besides these main processes of exploitation and exploration, knowledge retention has also been put forward as an important process in the context of open innovation, indicating the storage, maintenance and reuse of knowledge over time (Lichtenthaler and Lichtenthaler, 2009).

However, recently the open innovation approach has also been criticised. Trott and Hartmann (2009), for example, disagree with the open versus closed innovation dichotomy, since most companies are somewhere in between. 'Open' versus 'closed' is too simplistic and fails to adequately describe and analyse recent innovation strategies. Indeed, the collaboration between companies is often only ad hoc or project based and not all the relevant stakeholders are always involved in the innovation process (Bogers, 
2011). On top of that, organisations and collaborations can differ in their degree of openness as well. When practicing open innovation, there is a difficult balance between sharing knowledge and protecting knowledge, something which is referred to as the 'information paradox' (West et al., 2005; Bogers, 2011). Ortt and van der Duin (2008) also acknowledged this issue and put forward that in nowadays turbulent innovation environment, no single innovation management best practice exists anymore. Instead, they plead for so-called 'contextual innovation', or the fact that innovation management should be tailored towards the organisational and societal context of the innovating company. This is confirmed by Torkkeli et al. (2009) who found that the incentives to engage in open innovation are different for large versus small companies, while Mention (2011) discovered that a higher degree of innovation novelty shows a positive relation on the degree of cooperation and usage of external knowledge sources.

This overview stresses the importance of external networking, including all activities to acquire and maintain connections with external sources of social capital, including individuals and organisations. As such, this comprises both formal collaborative projects and more general and informal networking activities. Open innovation networks, which can range from informal links to formal R\&D alliances, allow firms to rapidly fill in specific knowledge needs without having to spend enormous amounts of time and money to develop that knowledge internally or acquire it through vertical integration (van der Vrande et al., 2009). In the light of the three open innovation processes, open innovation networks demand for three corresponding firm capabilities: absorptive capacity, or the ability to deal with knowledge exploration, connective capacity, or the ability to deal with knowledge retention, and desorptive capacity, or the ability to deal with knowledge exploitation (Lichtenthaler, 2011).

Within this paper, we will examine open innovation processes from a network-perspective, steering away from the strong firm-centric perspective which dominates a lot of open innovation research. We will not take into account the specific internal capabilities of firms, but instead focus on the nature, direction and motives for the knowledge and technology flows between the different actors involved in a Living $\mathrm{Lab}$, a recently emerged approach for generating innovation in a multi-actor ecosystem with a user-centric character.

\section{Living Labs as open innovation systems}

Living Labs as an innovation approach have emerged on the crossroads of open innovation and user innovation frameworks (Schuurman and De Marez, 2012). The term 'Living Lab' was originally used to describe a research facility that tries to overcome the artificial lab-context by providing a laboratory with all facilities of a regular home, optimised for multi-day or multi-week observational studies of individuals and constructed to resemble a 'real' home as closely as possible (Intille et al., 2005). Volunteer research participants inhabit these 'living laboratories' where the routine activities and interactions of everyday home life can be observed, recorded for later analysis, and experimentally manipulated (Eriksson et al., 2005). A fitting example of this kind of Living Labs can be found in Markopoulos and Rauterberg (2000) who compare Living Labs with so-called 'smart home' type projects. Whereas the latter type of projects acts as a showcase of an integrated vision of the 'home of the future', they define their Living Lab as a testing facility with as primary research goal to focus on how 
ubiquitous computing technology can be designed to fit the 'daily lives' of the Living Lab inhabitants. The prototype of this 'US vision' on Living Labs (Schuurman et al., 2011 ) is the MIT Placelab which tries to map the habits, activities and routines of users by placing sensors in a 1000 square foot simulated living room (Intille et al., 2005).

In Europe this original notion of Living Labs was reinterpreted based on the advances in both open and user innovation, and the movement was given a headstart by the support of EU-policy, especially in the domain of ICTs (Dutilleul et al., 2011). The major divergences from the US notion were a true real-world context (instead of a laboratory environment), users being treated as active co-creators instead of passive respondents and the multi-stakeholder aspect within the Living Lab constellation (Eriksson et al., 2005; Feurstein et al., 2008). Within this context, several international organisations representing different industrial ICT Living Lab initiatives were founded of which the European network of Living Labs (ENoLL) is the most well-known. However, when studying the different setups and conceptualisations of European Living Labs, the Living Lab concept appeared to be used in multiple ways (Eriksson et al., 2005; Ballon et al., 2007; Schuurman et al., 2013a). Although the Living Lab concept is being used for about ten years at the moment of this writing, this fuzziness is still one of the main issues dealt with in the academic literature in this domain. Different authors have tried to delineate the concept and to propose typologies to grasp this 'umbrella' concept. Følstad (2008) distinguishes two different Living Lab approaches within this 'European' notion:

1 Living Labs supporting context research and co-creation

2 Living Labs as extensions to testbeds.

The first is characterised by co-creation of new ICT-services and collection of information on the usage context, sometimes using ethnographic approaches to enable data collection (Pierson and Lievens, 2005). These Living Labs often focus on the early development phases (the 'fuzzy' front end of the NPD process), needs analysis and (iterative) design. Based on an identified problem, a solution is being developed in close interaction with end-users (Winthereik et al., 2009). Other Living Labs of this type are more evaluative in nature and focus on the iterative and collaborative fine-tuning of innovative products or services (Schuurman and De Marez, 2012). These Living Labs are a way to structure and manage user input and translate it into useful information (Almirall, 2008). Living Labs as extensions to testbeds, on the other hand, focus on the technical testing of innovations outside the laboratory. Testbed-like type of Living Labs can be found in the work of e.g., Ponce de Leon et al. (2006) and Zhong et al. (2006). They use the term to describe testbeds (controlled network environments for testing and validation) for ICT services. Følstad (2008) makes the observation that the opportunity to conduct real-world validation studies of testbed applications seems to be an important motivation for many of the Living Labs belonging to ENoLL, something which is also apparent in the work of Ballon et al. (2007).

Other authors stress the importance of collaboration and knowledge support activities as cardinal to a successful Living Lab (Feurstein et al., 2008; Buitendag et al., 2012). Cosgrave et al. (2013) connect the multi-stakeholder aspect of Living Labs to the concept of 'innovation districts', small regions which cluster innovative actors such as start-ups, creative industries and venture capitalists. These 'pockets of growth' are characterised by inter-firm collaboration and governmental support. As the multiple-stakeholder aspect is seen as a central element in this type of Living Labs, this also connects them to the 
literature on triple and quadruple helix-models, dealing with collaboration between universities, government, industry, and end-users (Arnkil et al., 2010). Collaborations like these have been claimed to facilitate a fluid exchange of ideas and technologies, with fewer barriers between academia and industry for information flows (Etzkowitz, 2008; Schuurman et al., 2012; Ståhlbröst and Holst, 2012).

Besides the different goals of a Living Lab, other authors analysed the different components and the different setups. A recurring element in most Living Labs is the ability to study innovations in a natural setting. This means that the technical infrastructure resembles the natural environment (in the case of a laboratory setting) or, preferable, that the technical infrastructure allows to capture user behaviour in the user's everyday environment. This element is associated to the material part of the Living Lab infrastructure. In the European context, the infrastructure substitutes the laboratory and allows users act and test in their natural environment. This infrastructure can consist of devices given to the users, mobile or fixed networks rolled out in a given environment, sensor networks, etc. In the case of technical networks and devices, this infrastructure enables long term Living Lab operations (such as monitoring of user activity) as well as facilitating short term Living Lab cases (products or services being tested out) (Ståhlbröst and Holst, 2012).

Besides the Living Lab infrastructure, Feurstein et al. (2008) define Living Labs as a systemic innovation approach in which all stakeholders in a product, service or application participate directly in the development. This definition stresses the multi-stakeholder aspect of the living lab infrastructure. The interactions and collaborations between the various stakeholders in the living lab infrastructure are also stressed by indicating the importance of an innovation ecosystem (Pasman et al., 2005).

Based on an empirical investigation of multiple Living Labs, Leminen et al. (2012) propose four different living lab actors based on their role: utilisers, enablers, providers and users.

- Utilisers aim to develop their businesses within the living lab ecosystem, mostly through short-term Living Lab cases. Their focus is on developing and testing their new products and services. These utilisers use Living Labs as a strategic tool to collect data on test-users of their products or services and collaborate with all stakeholders in the Living Lab ecosystem, including the end-users. These actors drive short-term Living Lab projects and can be regarded as short-term, ad hoc 'consumers or partners of the Living Lab'.

- Enablers can be various public sector actors, non-governmental organisations or financiers, such as towns, municipalities, or development organisations. This actor provides (financial) resources or policy support in order to start-up and maintain the Living Lab operations.

- Providers provide the other actors in the Living Lab with their product or service portfolio. They take care of the (material) infrastructure used for the Living Lab operations. Providers are mainly private companies that enter into Living Labs to co-develop new products, services and solutions to their own business or industry needs, and focus more on long-term results. They attain these goals through their involvement in general Living Lab operations and (possibly) in the Living Lab cases, driven by utilisers. 
- Users are the 'end-users' that are being involved in the Living Lab-operations and in the (short-term) Living Lab cases. In some Living Labs, existing user groups or user communities are involved, while in others the Living Lab operations themselves facilitate the formation of a living lab user community.

In the typology of Leminen et al. (2012) academic researchers are considered providers because they provide the necessary expertise on user research. Other research such as the triple and quadruple helix concepts, however, stresses the importance of universities as a distinct actor in the innovation ecosystem (Perkmann and Walsh, 2007; Etzkowitz, 2008; Arnkil et al., 2010; Cosgrave et al., 2013). Moreover, the contribution of academia is not limited to user research, as it can also include research on technical topics related to the focus of the Living Lab or policy and business researchers. Therefore, we distinguish researchers as a separate type of actor within the Living Lab anatomy.

Based on the various roles of the Living Lab actors and the central role of the infrastructure, we propose the following theoretical model of a Living Lab.

Figure 1 The anatomy of a Living Lab

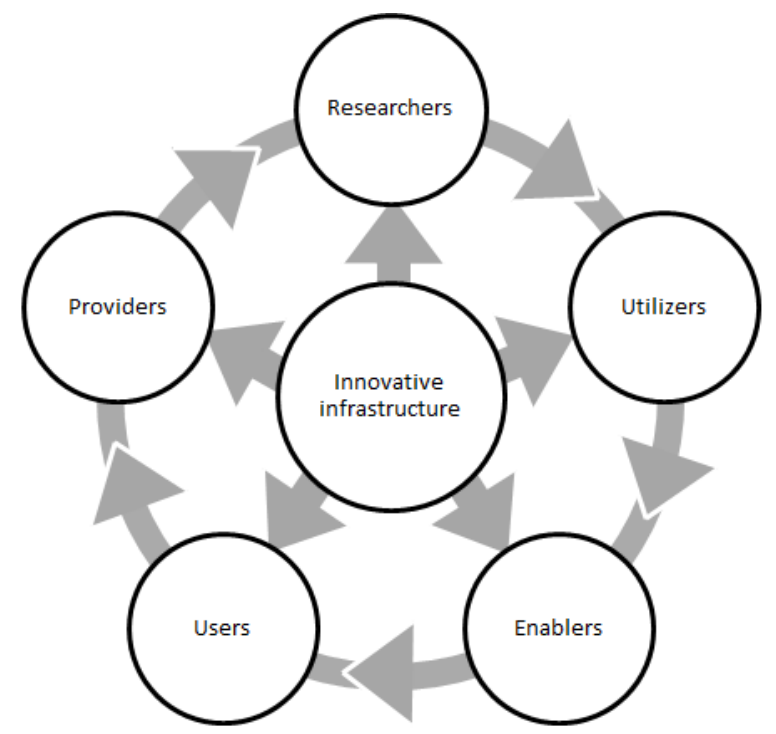

\section{Methodology and hypotheses}

In the next sections, we will validate this conceptual model of a Living Lab and investigate how value is created for each of the actors, how knowledge is being shared and how common goals can be achieved through the Living Lab innovation network by exchanging knowledge and enabling technology flows between these actors.

For this analysis we take an open innovation perspective to study the phenomenon of Living Labs as innovation systems, divergent from any of the previous studies on Living Labs. We will do this by means of an in-depth case study of the LeYLab Living Lab and the various cases that have ran within this Living Lab over a time span of two years, the formal duration of the Living Lab. 
Case study research excels at bringing an understanding of a complex issue or object and can extend experience or add strength to what is already known through previous research. Case studies are especially suited for investigating new and poorly understood processes, with their emphasis on detailed contextual analysis of a limited number of events or conditions and their relationships (Eisenhardt, 1989). Yin (1984) defines the case study research method as an empirical inquiry that investigates a contemporary phenomenon within its real-life context; when the boundaries between phenomenon and context are not clearly evident; and in which multiple sources of evidence are used. Given the complexity of the studied phenomenon, the multiple levels of analysis (actors, knowledge flows, etc.) and the participation of the author team in the Living Lab itself, this research design seems most appropriate.

For our analysis we were able to use the following data sources as first-hand involved actors in the Living Lab operations and Living Lab cases:

- official meeting minutes of all steering committees and of all official work package meetings

- the initial project proposal and all project reports

- all deliverables from the Living Lab operations and of the Living Lab cases

- all data from user research regarding Living Lab operations (intake surveys, domestication interviews, ...) and regarding the Living Lab cases

- field notes of all Living Lab cases meetings

- data from a short survey that was held amongst all actors participating in the Living Lab at the end of the Living Lab, which took more or less the form of a SWOT-exercise.

Based on our conceptual model and our literature review on open innovation and knowledge flows, we hypothesise that the motivations and the (potential) associated value for the different actors participating in the Living Lab are related to the specific roles they take in the Living Lab -constellation.

Table 1 Hypothesised motivation according to role in Living Lab

\begin{tabular}{|c|c|c|}
\hline & $\begin{array}{l}\text { Motivations to participate } \\
\text { in the Living Lab }\end{array}$ & Value created by the Living Lab \\
\hline \multirow[t]{2}{*}{ Utilisers } & Develop, test and learn & Need information \\
\hline & Exploration for innovation & Solution information \\
\hline Enablers & Meet policy goals & $\begin{array}{l}\text { Stimulating economic and } \\
\text { social value creation }\end{array}$ \\
\hline \multirow[t]{2}{*}{ Providers } & Exploitation of provided infrastructure & Market strategy \\
\hline & & Showcase infrastructure \\
\hline \multirow[t]{2}{*}{ Users } & Intrinsic motivations over extrinsic & Fun \\
\hline & motivations & Participation/empowerment \\
\hline \multirow[t]{2}{*}{ Researchers } & Exploiting implementable knowledge & Research data for academic \\
\hline & Exploring new knowledge & valorisation \\
\hline
\end{tabular}

For utilisers, we expect exploration as main motive in order to stimulate their innovation processes. The Living Lab provides the opportunity to get need information and solution 
information from the users involved in the Living Lab. For them, it is an ecosystem in which they can develop, test and learn. The researchers are expected to function as intermediaries between utilisers and users, as through their research they are able to abstract need and/or solution information from the users, which the utilisers are looking to explore. However, the Living Lab operations and activities also allow researchers to explore their own knowledge base (testing hypotheses, generating new theories/methodologies, etc.). They expect to generate research data that can be academically valorised. By doing so, researchers contribute to the knowledge retention of the Living Lab. For providers, we expect exploitation of the technology and/or knowledge they bring into the Living Lab network as main motive. They expect the Living Lab operations to provide them with input for their market strategy and roadmap. On top of that, the Living Lab enables them to showcase their innovative infrastructure. For users, we expect intrinsic motivations (such as task enjoyment and curiosity) to participate in the Living Lab to be dominant, as knowledge transfers between users and producers have found to be non-pecuniary. However, extrinsic motivations might also play a role (incentives and social value). As enablers contribute to the Living Lab with money or others assets that enable the Living Lab operations, these public organisations expect the Living Lab to fulfil some predefined policy goals. Mostly, this concerns the generation of social and/or economic value, such as increased neighbourhood cohesion or stimulating innovation and entrepreneurship. In the proposed conceptual model of a Living Lab, infrastructure has a central role since it facilitates collaboration among all actors and enables knowledge and technology spill-overs within the innovation ecosystem.

Besides these role-specific hypotheses, we also expect that actors engage in Living Labs because a too broad search for the relevant exploration or exploitation knowledge is inefficient, which draws them to collaborate with a smaller set of actors (Torkkeli et al., 2009). As the absorptive capacity of an actor is related to the degree of previous experience and trust with the other partners, we expect this to have an influence on the Living Lab operations (Bogers, 2011). Based on Mention's (2011) finding regarding cooperation and knowledge sources practices being associated to higher degrees of innovation novelty, we expect innovations being tested and created during Living Lab operations and cases to score high in terms of novelty. Finally, based on the observation that there exist asymmetric incentives for large and small firms in the case of open innovation (Torkelli et al., 2009), we expect company size to have an effect as well.

\section{Results and discussions}

LeYLab was a Living Lab situated in Flanders, Belgium which offered fibre internet access to a panel of households and organisations. This Living Lab was set up in September 2010 following the public call in Flanders for Living Labs with 'converged broadband access networks' as a central theme and was subsidised by IWT, the Flemish public investment organisation for innovation and science. The Living Lab was operational by July 2011 and its fibre network was located in two geographically restricted areas (city areas Buda and Overleie) in the City of Kortrijk. By building a Living Lab environment for next generation access (NGA), based upon fibre, testing innovative applications and services was made possible, meanwhile enabling and 
strengthening a user community and a collaborative ecosystem. Fibre offered unprecedented test facilities, in terms of bandwidth and quality of service and stimulates the ICT sector to develop innovative applications. Therefore, the shared goal of LeYLab was to stimulate innovation and to measure the relevance of new services for the personal lifestyle and living environment of the test users. Two main topics were chosen as focus for the Living Lab: innovative media and eHealth.

In order to set-up the Living Lab innovation network, a large consortium was composed of eight private partners, three public organisations and one public authority.

Alcatel-Lucent (http://www.alcatel-lucent.be), a multi-national technology company, took the project lead, provided the necessary equipment for the in-home usage of the fibre connection (modem, router, ...) and was responsible for the monitoring of the network (logging) and for the integration of all services and devices within the network. Belgacom (http://www.belgacom.be), the largest telecom provider in Belgium, deployed the fibre infrastructure and supervised the network. This was facilitated by the City of Kortrijk (http://www.kortrijk.be) who enabled the permits needed to install the network, started the communication loop with the potential test users and engaged local stakeholders for the Living Lab initiative. All research activity, panel recruitment and panel communication was executed by the iMinds (http://www.iminds.be) research institute. These four parties were active in both thematic domains and can be considered as responsible for the general Living Lab operations. Regarding the deployment of the network, a necessary precondition for all Living Lab operations and eventual Living Lab cases, this took much more time than expected. Time and effort for convincing people to participate and for effectively putting the fibre in the ground and installing the necessary devices in the homes of the users were underestimated by the consortium partners.

The other actors from the consortium could be allocated to one of the thematic domains, as they were involved in one of the two thematic use-cases that were predefined before the Living Lab was set-up. The first use-case consisted of the roll-out of an audiovisual content archiving and distribution system for local content. Zeticon (SME, a small university spin-off with a media asset management system, www.zeticon.com), Videohouse (SME, medium-sized AV technology provider, medium-sized company, http://www.videohouse.be) and Focus WTV (SME, medium-sized regional broadcaster, SME, http://www.focus-wtv.tv) were gathered to set-up an innovative media database allowing to share and archive multi-media content over the fibre network.

Table 2 Core Living Lab actors for LeYLab

\begin{tabular}{lcc}
\hline & Actor & Role \\
\hline Utilisers & $\begin{array}{c}\text { Two internal cases } \\
\text { external utilisers }\end{array}$ & Run applications and \\
Enablers & City of Kortrijk & Facilitation and communication \\
Providers & Alcatel-Lucent & Infrastructure deployment \\
Users & Belgacom & \\
Researchers & LeYLab panel members & Testers \\
& iMinds & User experience research \\
\hline
\end{tabular}


Table 3 Living Lab actors for the audiovisual pillar of LeYLab

\begin{tabular}{lcc}
\hline & Actor & Role \\
\hline Utilisers & Zeticon & $\begin{array}{c}\text { Develop and evaluate AV-content } \\
\text { archiving and distribution system }\end{array}$ \\
Videohouse & Promote and distribute local content \\
Providers & City of Kortrijk & Content provider \\
Users & Focus WTV & Sharing own content and \\
& LeYLab panel members & consulting content archive \\
Researchers & Other citizens & Research user experience \\
\hline
\end{tabular}

Table 4 Living Lab actors for the eHealth pillar of LeYLab

\begin{tabular}{|c|c|c|}
\hline & Actor & Role \\
\hline Utilisers & Televic Healthcare & $\begin{array}{l}\text { Evaluate remote video } \\
\text { chatting application }\end{array}$ \\
\hline Enablers & OCMW Kortrijk & $\begin{array}{l}\text { Enable roll-out amongst } \\
\text { target population }\end{array}$ \\
\hline \multirow[t]{2}{*}{ Providers } & Androme & Integrate solution in the network \\
\hline & In-Ham & Facilitate roll-out \\
\hline Users & $\begin{array}{l}\text { Elderly and disabled } \\
\text { LeYLab panel members }\end{array}$ & Test remote video chatting application \\
\hline \multirow[t]{2}{*}{ Researchers } & iMinds & Research user experience \\
\hline & U-Sentric & Research usability \\
\hline
\end{tabular}

The second use-case, within the eHealth thematic domain, dealt with a solution for remote video communication for elderly and disabled people that could be used on a regular TV-set. The following consortium partners were involved: Androme (SME, medium-sized ICT support, http://www.androme.com) provided specific technological knowhow on operating and integrating networked ICT solutions, In-Ham (small public sector organisation concerning eHealth, http://www.inham.be) added their specific expertise on dealing with elderly and disabled people, U-Sentric (SME, medium-sized university spin-off specialised in usability testing, http:/www.usentric.be) was part of the consortium because of their expertise in usability testing of eHealth technologies, OCMW Kortrijk (public health organisation from the city of Kortrijk) added knowhow of the local population and health ecosystem, and Televic Healthcare (eHealth technology company, http://www.televic-healthcare.com) provided their XTramira solution which enables remote communication with a set-top-box connected to a TV-set.

These use-cases were also meant to provide the first FTTH and Living Lab applications to the test users, so they could start testing, and as showcases to attract external utilisers to the Living Lab.

However, besides the slow deployment of the Living Lab infrastructure, both usecases also suffered from various other difficulties. These resulted in the media case being up and running only during the final month of the Living Lab and the eHealth use-case not being implemented at all because of difficulties integrating the solution on the fibre infrastructure and because of the lack of panel members who needed healthcare. 
The aforementioned issues regarding the general Living Lab operations also affected the generation of external Living Lab cases as the lack of cases and research material made it hard to convince external utilisers to come to the Living Lab. Eventually, three external Living Lab cases ran in the Living Lab: Poppidups (a virtual puppetry application playable online with cards containing a unique QR-code, created by the SME Prophets, specialised in online marketing), Cloudfriends (a network optimisation application that also included Wi-Fi configuration based on user feedback developed by SME and start-up company Cloudfriends) and WeePeeTV (an over-the-top streaming TV application developed by SME WeePee New Media Ventures). In all three cases users were involved in testing, evaluating and co-creation of the innovative applications.

The next section reviews our main hypothesis based on the actual Living Lab experiences of the different actors.

The external utilisers were able to explore, test and develop their innovations based on user feedback and user behaviour captured by the researchers, who abstracted user needs from the data through co-creation sessions, observations and surveys. In the case of Cloudfriends, the Living Lab case led to an expressed user need that made the utiliser redesign its application, something which resulted in exploiting the technology to a foreign multi-national. When going through the notes from the intake meeting, it became apparent that this utiliser already thought of exploiting its technology, possibly to one of the providers of the Living Lab. Other utilisers focused on exploration instead of exploitation. All external utilisers were able to utilise the knowledge from the Living Lab case for the innovation development, but in two of the three instances, extra test users had to be recruited outside of the Living Lab, and only one of the innovations explicitly benefitted from the technical infrastructure (WeePeeTV).

The researchers did function as intermediaries between utilisers and users, but had to define other research activities because of the lack of internal and external cases in order to activate the panel members. The aggregation of research activities provided enough data and material for academic valorisation. As discussed in the next paragraph, collaboration with the providers of the Living Lab also resulted in mutual benefits due to the exchange of knowledge. While academic valorisation of research data gathered within the Living Lab enhanced the desorptive capacity of this actor, the enabling role towards utilisers and providers defines the research actor as an innovation broker with connective capacity.

The providers of the main Living Lab infrastructure, Alcatel-Lucent and Belgacom, were able to exploit their technologies (the physical fibre network and the related devices such as the modems) as they were able to demonstrate their added value, thus also increasing their desorptive capacity. Although, the Living Lab did not generate 'the' killer application that would make fibre internet a necessity, research data from surveys showed that the users were nonetheless excited with the sheer speed of the network and technical logging data indicated that they started using more bandwidth when they had 'domesticated' their fibre installation (Schuurman et al., 2013b). This logging data enabled an additional exploration of user behaviour, which could be used for future developments. This logging data was exchanged and confronted with other research data from the researchers, which provided additional value for the providers, who complemented their logging data with self-reporting data, and for the researchers, who could verify the self-reported data with objective log files. For the providers within the thematic use-cases, the motives were mixed. Androme mainly wanted to explore its knowledge regarding integration of ICT solutions and InHam wanted to further establish 
itself as sector organisation for eHealth, whereas Focus WTV looked at the use-case as a potential new source for exploiting its content. In terms of motives, these appeared to have both an exploring and exploiting nature, increasing absorptive and desorptive capacities of the organisations.

Surveys indicated that users mainly participated because of the infrastructure (extrinsic motivation) and out of curiosity (intrinsic motivation), so the infrastructure itself was considered an incentive. An unforeseen effect of the Living Lab activities was a strong sense of community among the test users. The geographic proximity, the collaborative interactions and the shared infrastructure seemed to increase social cohesion, which became apparent during offline gatherings where the participation of panel members was very high and by spontaneous actions such as helping each other in case of technical problems. The strong infrastructural component of the Living Lab appeared to be a very important aspect for the users and had a positive influence on the willingness to participate in research activities.

The City of Kortrijk as enabler was able to establish itself as an innovative city towards its citizens and towards other cities and stakeholders. This resulted in the inclusion in a large European smart city-project during the running time of the Living Lab and also in LeYLab becoming an official member of ENoLL. The community project based on the internal media case could not be executed because of the late realisation, but this was compensated by the spontaneous community building effect of the Living Lab. The Living Lab both increased social value (increased social cohesion) and supported SMEs in the development of innovations (economic value).

The FTTH as a central innovative infrastructure, had a double role in this Living Lab. On the one hand, the roll out en set-up of the hardware delayed the actual kick-off of the Living Lab project. On the other hand, due to the close collaboration which was needed to achieve the operational goals, this also stimulated the core partners to establish an open relationship and increased the level of trust between the infrastructure partners.

From the general hypotheses, the tendency towards collaboration with a smaller set of partners because of efficiency reasons could be confirmed. On paper 12 partners were involved in the LeYLab-consortium, but in reality, the main operations and activities were carried out by only four partners that exchanged a lot of knowledge. This was related to the strong emphasis on the infrastructure of the Living Lab which required a coordinated effort of these partners. The other consortium partners had different goals and interests, mainly related to the two thematical use-cases, without specific interest in the infrastructure itself. As Belgacom and Alcatel-Lucent both had an interest in exploiting their fibre-related technologies and devices, they were actively looking for 'proof' that there was a user interest in fibre internet and that external companies would succeed in finding a 'killer app' that required fibre. Therefore, they were also most active in the exploitation of the Living Lab infrastructure itself, i.e., attracting external utilisers. The researchers from iMinds also benefitted from the activity within the Living Lab as this generated data, potential for knowledge exploitation. Kortrijk as enabler wanted to profile itself as a 'smart' and innovative city, which also made them very active throughout the total time frame of the Living Lab. Common elements between these core Living Lab actors are:

1 common of compatible long-term goals

2 a higher availability of resources, related to the size of the organisation 
3 the close interaction for the roll-out of the technical infrastructure

4 none of them were utilisers only.

Trust was an important element especially for the external recruitment of utilisers. The presence of one of the providers from the eHealth-case appeared to refrain certain external utilisers to come to the Living Lab as they feared that their ideas would be picked up by this firm. This became apparent during the business development activities undertaken to attract external utilisers. Three companies, which we cannot mention because of reasons of confidentiality, were initially interested in testing and co-creating their innovations in LeYLab, but eventually decided not to participate because of the presence of Televic Healthcare. In one of these three cases, the potential utiliser decided to engage in bilateral contract research with one of the research parties instead. This clearly illustrates the limitations to the degree of openness in the development of innovations.

For the Cloudfriends case, the presence of a competitor was on the contrary an incentive to engage in the Living Lab, but only because this external utiliser was already aiming at possibly exploiting its technology from the start.

The expectation that the Living Lab attracts innovation with a high degree of novelty could be confirmed as well. WeePeeTV was the first over-the-top streaming TV service available in Flanders, the easy home Wi-Fi access and the auto-correcting functionalities of the Cloudfriends-app were also new to the Flemish market and the concept of a virtual puppetry theatre was also the first of its kind. The two internal use-cases were less novel in terms of functionality, but wanted to innovate in terms of ease-of-use for the target population. Mixed evidence could be found for the hypothesis regarding company size. In general, the large companies had more motives related to exploitation and acted as providers, whereas the SMEs were more likely to be utilisers of the Living Lab and looked to explore their knowledge base in order to add to further develop and fine-tune their innovations. However, there are also examples that show the exact opposite. In the Cloudfriends case the start-up company was looking to further explore its technology, but in the meantime kept in mind to potentially sell their technology to one of the providers, and by entering the Living Lab they were able to exploit and sell their technology, albeit to an external company. Televic is an example of a larger company wanting to exploit its technology in the role of utiliser, something which turned out to be unsuccessful.

\section{Conclusions}

Companies still struggle to adequately manage their innovation processes in order to create successful and innovative products and services. Different literature streams such as the user innovation and open innovation frameworks have pointed out the importance of reaching out of the firm boundaries and collaborating with other stakeholders, but no single 'best practice' approach has been defined yet. We have proposed Living Lab s as open innovation systems where different ideas and concepts can be explored and validated with different actors, facilitating the exchange of knowledge and technologies. This paper proposes and illustrates a conceptual framework that analyses the different actors within a Living Lab ecosystem. Clustered around a central infrastructure, five types of actors are identified and analysed. The different roles that are assigned to the 
different actors are associated to certain open innovation activities, but during the living lab-operations, some actors may switch or combine roles.

The three external utilisers of LeYLab and five of the twelve consortium partners were Flemish SMEs. This indicates that the studied Living Lab clearly succeeded in attracting SMEs to engage in open innovation, a group that was lagging behind (van de Vrande et al., 2009). The role of utiliser seems to be most fitting to them as this allows them to benefit from the Living Lab -infrastructure in order to explore their technology, with the potential to be noticed by a partner inside or outside the Living Lab which offers exploitation possibilities. Because of an absence of common goals, scarce resources and the short-term nature of this actor, full consortium membership is not needed or hard to maintain. The role of provider of the Living Lab infrastructure, on the other hand, seems to be best suited for larger companies with more established and stable technologies, as the smaller providers from the case study failed to deliver or engage themselves in the Living Lab. Besides exploitation of their infrastructure, Living Labs also facilitate the exploration of new ideas and technologies through the multiple (external) Living Lab cases that take place in the Living Lab.

The researchers in the Living Lab have an important mediating role between the utilisers and the users, as they make information regarding user needs 'unsticky' (von Hippel, 2005) by means of specific research methodologies. The enablers of the Living Lab play an essential role in supporting and facilitating the Living Lab. Therefore, Living Lab activities should be tailored towards the policy objectives of the enablers. A city appeared to be quite suited for this role as they have a direct link to the citizens (potential test users), local private companies (potential utilisers) and local organisations (potential providers). The local aspect of the 'city Living Lab' also fostered a strong sense of community building among the test users, something which is less likely to occur in a geographically dispersed Living Lab.

The thematic focus of the Living Lab and the number of partners are of utmost importance in order to be able to align the goals of the different partners, something which did not fit well in the case study, but which was solved in a natural way through the actual degree of collaboration between the parties who did share common goals. In LeYLab, this was the case for the four partners responsible for the actual set-up and roll-out of the infrastructure. This required an orchestrated effort and in order to get insights into the actual usage and behaviour of test-users, testing of external applications and services was required.

Another important lesson is that the definition of internal use cases is of utmost importance in order to 'headstart' the Living Lab with cases that activate the users and generate research data and showcases to attract external utilisers. In LeYLab, two internal use-cases were planned, but these took too much time or suffered from too many set-backs to actually get the Living Lab up and running. This resulted in only three external cases being carried out in the Living Lab which started only towards the formal end of the Living Lab. Early Living Lab activity is important to confirm the consortium, engage the user community and to attract external utilisers.

The main limitation of this paper is that it draws upon the experiences of one Living Lab. Therefore, it is difficult to generalise the insights. However, the networked and systemic nature of Living Lab s and innovation processes running in these Living Lab s lend themselves towards a case study research approach, and this paper is the first to analyse these processes, set-up, roles and outcomes taking an open innovation 
perspective. Future research might reassess the given hypotheses in a different Living Lab setting or focus on fewer relations or actors and assess them on a larger scale, also taking into account the outcomes of innovation processes and cases occurring in Living Labs. Furthermore, it might be interesting to validate these findings in other domains, with other infrastructures and non-geographically centralised Living Lab initiatives. Finally, further academic elaboration is needed on the difference between actors and roles, with a special focus on the combination of roles within a Living Lab project.

\section{References}

Almirall, E. (2008) 'Living Labs and open innovation: roles and applicability', The Electronic Journal for Virtual Organizations and Networks, Vol. 10, No. 3, pp.21-26.

Almirall, E. and Wareham, J. (2011) 'Living Labs: arbiters of mid- and ground-level innovation', Technology Analysis \& Strategic Management, Vol. 23, No. 1, pp.87-102.

Andriopoulos, C. and Lewis, M.W. (2009) 'Exploitation-exploration tensions and organizational ambidexterity: managing paradoxes of innovation', Organization Science, Vol. 20, No. 4, pp.696-717.

Arnkil, R., Järvensivu, A., Koski, P. and Piirainen, T. (2010) 'Exploring the quadruple helix', Report of Quadruple Helix Research for the CLIQ Project, Work Research Centre, University of Tampere, Tampere, Finland.

Ballon, P., Pierson, J. and Delaere, S. (2007) 'Fostering innovation in networked communications: test and experimentation platforms for broadband systems', in Heilesen, S. and Jensen, S. (Eds.), Designing for Networked Communications: Strategies, Development, pp.137-166, ISI Global, London.

Bogers, M. (2011) 'The open innovation paradox: knowledge sharing and protection in R\&D collaborations', European Journal of Innovation Management, Vol. 14, No. 1, pp.93-117.

Bogers, M. and West, J. (2012) 'Managing distributed innovation: strategic utilization of open and user innovation', Creativity and Innovation Management, Vol. 21, No. 1, pp.61-75.

Brem, A. and Viardot, E. (2013) Evolution of Innovation Management: Trends in an International Context, Palgrave Macmillan, Hampshire.

Buitendag, A.A., van der Walt, J.S., Malebane, T. and de Jager, L. (2012) 'Addressing knowledge support services as part of a living lab environment', Issues in Informing Science \& Information Technology, Vol. 9, No. 9, pp.221-241.

Chandler, A.D. (1977) The Visible Hand: The Managerial Revolution in America Business, Belknap Press., Camebridge, MA.

Chesbrough, H. (2003) Open Innovation. The New Imperative for Creating and Profiting from Technology, Harvard Business School Press, Boston.

Chesbrough, H. (2005) 'Open innovation: a new paradigm for understanding industrial innovation', in Chesbrough, H., Vanhaverbeke, W. and West, J. (Eds.): Open Innovation: Researching a New Paradigm, Oxford University Press, Oxford.

Chesbrough, H. and Crowther, A.K. (2006) 'Beyond high tech: early adopters of open innovation in other industries', $R \& D$ Management, Vol. 36, No. 3, pp.229-236.

Chesbrough, H., Vanhaverbeke, W. and West, J. (Eds.) (2008) Open Innovation: Researching a New Paradigm: Researching a New Paradigm, OUP, Oxford.

Cooper, D. (2001) 'Innovation and reciprocal externalities: information transmission via job mobility', Journal of Economic Behavior \& Organization, Vol. 45, No. 4, pp.403-425.

Cosgrave, E., Arbuthnot, K. and Tryfonas, T. (2013) 'Living Labs, innovation districts and information marketplaces: a systems approach for smart cities', Procedia Computer Science, Vol. 4, No. 16, pp.668-677. 
Dutilleul, B., Birrer, F.A.J. and Mensink, W. (2011) 'Unpacking European Living Labs: analysing innovation's social dimensions', Central European Journal of Public Policy, Vol. 4, No. 1, pp.60-85.

Eisenhardt, K. (1989) 'Building theories from case study research', Academy of Management Review, Vol. 14, No. 4, pp.532-550.

Enkel, E., Gassmann, O. and Chesbrough, H. (2009) 'Open R\&D and open innovation: exploring the phenomenon', R\&D Management, Vol. 39, No. 4, pp.311-316.

Eriksson, M., Niitamo, V.P. and Kulkki, S. (2005) State-of-the-Art in Utilizing Living Labs Approach to User-Centric ICT Innovation - A European Approach (White paper) [online] http://www.vinnova.se/upload/dokument/verksamhet/tita/stateoftheart livinglabs_eriksson200 5.pdf (accessed 01/05/2013).

Etzkowitz, H. (2008) The Triple Helix: University-Industry-Government. Implications for Policy and Evaluation, SISTER, Stockholm.

Evans, P. and Wolf, B. (2005) 'Collaboration rules', Harvard Business Review, Vol. 83 Nos. 7-8, pp.96-104.

Feurstein, K., Hesmer, A., Hribernik, K.A., Thoben, T.D. and Schumacher, J. (2008) 'Living Labs: a new development strategy', in Schumacher, J. and Niitamo, V.P. (Eds.): European Living Labs - a New Approach for Human Centric Regional Innovation, Wissenschaftlicher, Berlin.

Følstad, A. (2008) 'Living Labs for innovation and development of communication technology: a literature review', The Electronic Journal for Virtual Organisations and Networks, August, Vol. 10, No. 7, pp.99-131.

Intille, S.S., Larson, K., Beaudin, J.S., Nawyn, J., Tapia, E.M. and Kaushik, P. (2005) 'A living laboratory for the design and evaluation of ubiquitous computing technologies', in $\mathrm{CHI}$ ' 05 Extended Abstracts on Human Factors in Computing Systems - CHI '05, ACM Press, New York, New York, USA.

Leminen, S., Westerlund, M. and Nyström, A. (2012) 'Living Labs as open-innovation networks', Technology Innovation Management Review, September, Vol. 2, pp.6-11.

Lichtenthaler, U. (2011) 'Open innovation: past research, current debates, and future directions', The Academy of Management Perspectives, Vol. 25, No. 1, pp.75-93.

Lichtenthaler, U. and Lichtenthaler, E. (2009) 'A capability-based framework for open innovation: complementing absorptive capacity', Journal of Management Studies, Vol. 46, No. 8, pp.1315-1338.

Markopoulos, P. and Rauterberg, G.W. (2000) LivingLab: A white paper, IPO Annual Progress Report 35, pp.53-65 [online] http://www.idemployee.id.tue.nl/p.markopoulos/downloadablePapers/LivingLabWhitePaper.p df (accessed 01/05/2013).

Mention, A. (2011) 'Co-operation and co-opetition as open innovation practices in the service sector: which influence on innovation novelty?', Technovation, Vol. 31, No.1, pp.44-53.

Ortt, J. and van der Duin, P. (2008) 'The evolution of innovation management towards contextual innovation', European Journal of Innovation Management, Vol. 11, No. 4, pp.522-538.

Pasman, G., Stappers, P.J., Hekkert, P.P.M. and Keyson, D. (2005) 'The IDStudioLab 2000-2005', in: Achten, H., Dorst, K., Tappers, P.J. and de Vries, B. (Eds.): Design Research in the Netherlands, pp.193-204, Design Systems, Eindhoven.

Perkmann, M. and Walsh, K. (2007) 'University-industry relationships and open innovation: towards a research agenda', International Journal of Management Reviews, Vol. 9, No. 4, pp.259-280.

Pierson, J. and Lievens, B. (2005) 'Configuring Living Labs for a 'thick' understanding of innovation', Conference Proceedings of EPIC 2005 (Ethnographic Praxis in Industry Conference), American Anthropological Association, USA, pp.114-127. 
Ponce de Leon, M., Eriksson, M., Balasubramaniam, S. and Donelly, W. (2006) 'Creating a distributed mobile networking testbed environment - through the Living Labs approach', in Proceedings of the Second International IEEE/Create-Net Conference on Testbeds and Research Infrastructures for the Development of Networks and Communities, pp.135-139.

Pyka, A. and Küppers, G. (2002) Innovation Networks: Theory and Practice, Edward Elgar Publishing, Northhampton, MA, USA.

Sawhney, M. and Prandelli, E. (2000) Beyond Customer Knowledge Management: Customers as Knowledge Co-creators, Idea Group Publishing, Hershey, PA, USA.

Schuurman, D. and De Marez, L. (2012) 'Structuring user involvement in panel-based Living Labs', Technology Innovation Management Review, September, Vol. 2, No. 9, pp.313-338.

Schuurman, D., Baccarne, B., Kawsar, F., Seys, C., Veeckman, C., De Marez, L. and Ballon, P. (2013b) 'Living Labs as quasi-experiments: results from the Flemish LeYLab', Presented at the XXIV ISPIM Conference - Innovating in Global Markets: Challenges for Sustainable Growth, Helsinki, Finland.

Schuurman, D., De Moor, K., De Marez, L. and Evens, T. (2011) 'A living lab research approach for mobile TV', Telematics and Informatics, Vol. 28, No. 4, pp.271-282.

Schuurman, D., Lievens, B., De Marez, L. and Ballon, P. (2012) 'Innovation from user experience in Living Labs: revisiting the "innovation factory"-concept with a panel-based and user-centered approach', presented at the XXIII ISPIM Conference, Barcelona, Spain.

Schuurman, D., Mahr, D., De Marez, L., and Ballon, P. (2013a) 'A fourfold typology of Living Labs: an empirical investigation amongst the ENoLL community', presented at ICE \& IEEEITMC 2013, The Hague, Netherlands.

Ståhlbröst, A. and Holst, M. (2012) The Living Lab Methodology Handbook, Luleå University of Technology and CDT - Centre for Distance-spanning Technology, Luleå, Sweden.

Torkkeli, M.T., Kock, C.J. and Salmi, P.A. (2009) 'The "open innovation" paradigm: a contingency perspective', Journal of Industrial Engineering and Management, Vol. 2, No. 1, pp.176-207.

Trott, P. and Hartmann, D. (2009) 'Why 'open innovation' is old wine in new bottles', International Journal of Innovation Management, Vol. 13, No. 4, pp.715-736.

van de Vrande, V., de Jong, J., Vanhaverbeke, W. and de Rochemont, M. (2009) 'Open innovation in smes: trends, motives and management challenges', Technovation, Vol. 29, Nos. 6-7, pp.423-437.

von Hippel, E. (1976) 'The dominant role of users in the scientific instrument innovation process', Research Policy, Vol. 5, No. 3, pp.212-239.

von Hippel, E. (2005) Democratizing Innovation, MIT Press, Cambridge, MA.

West, J. and Lakhani, K.R. (2008) 'Getting clear about communities in open innovation', Industry and Innovation, Vol. 15, No. 2, pp.223-231.

West, J., Vanhaverbeke, W. and Chesbrough, H. (2005) Open Innovation: A Research Agenda [online] http://www.openinnovation.net (accessed 01/05/2013).

Westerlund, M., and Leminen, S. (2011) 'Managing the challenges of becoming an open innovation company: experiences from Living Labs', Technology Innovation Management Review, October, Vol. 1, No. 10, pp.19-25.

Winthereik, J.C.T., Malmborg, L. and Andersen, T.B. (2009) 'Living Labs as a methodological approach to universal access in senior design', Lecture Notes in Computer Science 5614, pp.174-183.

Yin, R. (1984) Case Study Research, Beverly Hills, CA: Sage Publications.

Zhong, X., Chan, H., Rogers, T.J., Rosenberg, C.P. and Coyle, E. (2006) 'The development and eStadium testbeds for research and development of wireless services for large-scale sports venues' presented at the Second International Conference on Testbeds and Research Infrastructures for the Development of Networks and Communities, TRIDENTCOM 2006, IEEE. 